\title{
CÂNCER COLO-RETAL HEREDITÁRIO
}

\section{COLORECTAL HEREDITARY CANCER- UPDATE}

\author{
Marcus Valadão, TCBC-RJ' ${ }^{\text {; }}$ Leonaldson dos Santos Castro, TCBC-RJ ${ }^{2}$
}

\section{INTRODUÇÃO}

Aproximadamente $80 \%$ dos pacientes desenvolvem o câncer colorretal (CCR) de forma esporádica, enquanto que em 20\% há uma susceptibilidade hereditária à neoplasia. Das formas hereditárias o Câncer Colo-retal Hereditário não Polipose (CCHNP) é a mais comum, sendo responsável por 20 $-30 \%$ destes, o que equivale a $3 \%$ a $5 \%$ de todas as neoplasias colorretais ${ }^{1}$. Classicamente como é conhecida, a síndrome de Lynch I e II é uma doença autossômica dominante sendo cinco vezes mais freqüente que a polipose adenomatosa familiar $(\mathrm{PAF})^{2}$ e é decorrente da mutação do gen responsável pelo sistema de reparo do DNA. O envolvimento colônico isolado ocorre na Síndrome Lynch I, enquanto no subtipo II ocorre câncer colorretal associado a outras neoplasias, como de endométrio, ovário, mama, estômago, intestino delgado, hepatobiliar, pâncreas, ureter e de pelve renal ${ }^{3}$. A penetrância está em torno de $80 \%{ }^{4}$, ou seja, indivíduos que herdam esta mutação têm uma chance de aproximadamente $80 \%$ de desenvolvimento de CCR.

\section{BASES GENÉTICAS}

As mutações genéticas que causam CCHNP estão no DNA dos genes da classe MMR (Mismatch Repair gene - reparadores de emparelhamento) que corrigem erros durante a replicação do DNA. Dentre os vários genes que participam do sistema de reparo do DNA, as mutações que ocorrem no hMLH1 (cromossomo 3p21-3) e hMSH2 (2p22-p21) são responsáveis por $90 \%{ }^{5}$ das mutações detectadas na CCHNP. Mutações do hMSH6 (2p16) foram encontradas em algumas famílias e raras mutações no hPMS1 (2q31-33) e hPMS2 (7p22) foram descritas. Mutações no hMSH2 levam a um risco significativamente aumentado de neoplasia extracolônica. Todas as células de indivíduos afetados carreiam um alelo não funcionante do gene MMR. Se o alelo é perdido ou inativado, a célula não pode mais reparar erros de emparelhamento de DNA que inevitavelmente ocorrem durante a replicação do DNA. Células com genes MMR defeituosos acumulam mutações numa taxa muito alta (1000 vezes maior que as células normais), o que favorece o desenvolvimento da oncogênese.
Quando o tecido tumoral de pacientes portadores de CCHNP é analisado, encontra-se instabilidade genética em seqüências repetidas de bases no DNA, também chamadas de microssatélites, cuja função ainda é desconhecida. Esta instabilidade ocorre devido à deficiência dos genes de reparo, o que caracteriza esses tumores como positivos para erros de replicação. Alterações nas seqüências microssatélites resultam em mutações dos genes que funcionam na regulação do crescimento celular. $O$ gen codificador do TGF- $\beta$ (Transforming growth factor $\beta=$ fator de transformação de crescimento II) contém um microssatélite que é susceptível à mutação quando há predisposição à instabilidade microssatélite (MSI- Microsatellite Instability). Mutações nesse gene tornam o receptor TGF- $\beta$ (que é um inibidor de crescimento de células colônicas epiteliais normais) irresponsivo. Mais de $90 \%$ dos tumores com MSI demonstram instabilidade nesse gen, conferindo-lhe importante papel na gênese tumoral do CCHNP. MSI também determina mutações no gene BAX, que é um importante promotor de apoptose $^{6}$. Mutações nesse gene podem acelerar a seqüência adenoma-carcinoma, o que é encontrado em tumores do CCHNP.

\section{APRESENTAÇÃO CLÍNICA E DIAGNÓSTICO}

No CCHNP, as neoplasias tendem a ocorrer preferencialmente no cólon direito $(60-70 \%$ ocorrem proximais à flexura esplênica), mais precocemente (por volta dos 45 anos de idade), têm taxa aumentada de tumores metacrônicos e sincrônicos (20\%), ao contrário do que ocorre na forma esporádica, as quais são diagnosticadas em pacientes com média de 65 anos e predominam no cólon esquerdo. Ainda, no CCHNP há uma proporção aumentada de tumores mucinosos e de mais alto grau de diferenciação, bem como a infiltração linfática da margem tumoral ${ }^{7-9}$, entretanto, a sobrevida é comparativamente melhor em relação aos casos esporádicos, em parte devido à apresentação tumoral menos avançada e, mesmo comparações estádio a estádio, demonstraram vantagem de sobrevida em CCHNP sobre pacientes com câncer coloretal esporádico no estádio III ${ }^{10}$.

Em decorrência da ausência de sinais clínicos que possam predizer a suscetibilidade ao CCHNP, a história fami-

1. Cirurgião Oncológico do INCA; Mestre em Ciências pela Universidade Federal de São Paulo.

2. Chefe do Grupo de Patologia do Câncer Colo-reto-anal do INCA; Mestre e Doutor em Cirurgia pela UFRJ; FACS.

Recebido em 06/11/2006

Aceito para publicação em 07/01/2007

Conflito de interesses: nenhum

Fonte de financiamento:nenhuma

Trabalho realizado no Instituto Nacional do Câncer - INCA - RJ. 
liar tem sido o método principal em identificar pacientes de risco. Em 1990, o Grupo Colaborativo Internacional (GCI) em CCHNP criou os critérios de Amsterdan I com a finalidade de identificar as famílias de risco.

\section{Critérios de Amsterdan I (1990) ${ }^{8}$}

Para que haja identificação clínica de CCHNP serão necessários no mínimo, três parentes com CCR e mais os seguintes dados:

- Um paciente acometido deve ser parente de primeiro grau dos outros dois;

- Duas ou mais gerações sucessivamente acometidas;

- Pelo menos um dos parentes acometidos com diagnóstico de CCR com idade inferior a 50 anos;

- Exclusão do PAF;

- Tumores examinados histologicamente.

Estes critérios de Amsterdan I eram restritivos, pois excluíam membros da família que apresentavam tumores extracolônicos, eles foram então expandidos, dando origem aos critérios de Amsterdan II (Tabela 1).

Apesar do crescente conhecimento das bases genéticas do CCHNP, ainda não está completamente estabelecido um algoritmo para teste genético em pacientes de risco. Muitos autores advogam que o teste inicial para identificação desta síndrome seria a pesquisa de instabilidade de microssatélite (MSI). A MSI é pesquisada pela comparação das sequiências microssatélites das células tumorais com as do tecido normal. Variabilidade entre estes dois clones celulares indica MSI. Diante disso, o Instituto Nacional de Câncer americano (NCI) desenvolveu os critérios de Bethesda (Tabela 2) durante a conferência de consenso realizada em 1997. Esse consenso sugere que pacientes que apresentem estes critérios devem ser submetidos à pesquisa de instabilidade de microssatélite para o diagnostico de CCHNP.

Esta conferência propôs a análise de cinco marcadores de microssatélite para a identificação de MSI no CCHNP. Este painel inclui duas repetições mononucleotídeas (BAT25 e BAT26) e três dinucleotídeas (D5S346, D2S123 e D17S250). A presença de instabilidade em $40 \%$ ou mais dos marcadores (dois ou mais dos cinco marcadores do painel de Bethesda) é definido como MSI-H (Instabilidade microssatélite de alta frequência), enquanto que instabilidade em $20 \%$ a $40 \%$ dos marcadores é definido como MSI-L (Instabilidade microssatélite de baixa frequência). Tumores sem instabilidade comprovada (20\% ou menos) são designados MSS (estabilidade microssatélite). Desta forma, a presença de MSI-H é indicador do diagnóstico de CCHNP. O real significado da MSI-L ainda é motivo de debate, havendo opiniões de que esta alteração possa estar presente em alguns tumores ${ }^{13}$.

Em 2002, os critérios originais foram revisados e ampliados $^{14}$, e em 2004, uma nova conferência os revisou, incluindo os achados da Síndrome de Muir-Torres (variante do CCHNP associado a múltiplos adenomas sebáceos cutâneos, carcinomas sebáceos e ceratoacantomas).

Outros algoritmos para rastreamento de CCHNP têm sido testados, utilizando-se de modelos quantitativos baseados em parâmetros clínicos. Wijnen e colaboradoes ${ }^{15}$ criaram um modelo estatístico (utilizando regressão logística) capaz de predizer a possibilidade do diagnóstico de CCHNP basea-

Tabela 1 - Critérios de Amsterdan II $^{11}$.

Identificação clínica do HNPCC requer três ou mais parentes com neoplasia associada a HNPCC (CCR ou câncer de endométrio, intestino delgado, ureter ou pelve renal) mais o seguinte:

- Um paciente acometido deve ser parente de primeiro grau dos outros dois;

- Duas ou mais gerações sucessivamente acometidas;

- Um ou mais indivíduo afetado com diagnóstico em idade inferior a 50 anos;

- FAP excluído em qualquer dos casos de CCR;

- Tumores examinados histologicamente.

\section{Tabela 2 - Critérios de Bethesda $1997^{12}$.}

- Câncer em família que preenchem os critérios de Amsterdan;

- Dois tumores relacionados a HNPCC, incluindo CCR sincrônico ou metacrônico, ou associado com câncer extra-colônico (endométrio, ovário, gástrico, hepatobiliar, de intestino delgado ou carcinoma de células transicionais de ureter ou pelve renal);

- CCR e um parente de primeiro grau com CCR ou câncer extra-colônico associado a HNPCC, ou adenoma colorretal com um dos cânceres diagnosticados em idade inferior a 50 anos e o adenoma diagnosticado em idade inferior a 40 anos;

- CCR ou carcinoma de endométrio em idade inferior a 45 anos;

- CCR localizado em cólon direito com um padrão indiferenciado (sólido, cribiforme) ao exame histológico em idade inferior a 45 anos;

- CCR com células em anel de sinete em idade inferior a 45 anos;

- Adenoma colo-retal em idade inferior a 40 anos. 
do nas seguintes variáveis: idade média ao diagnóstico de câncer colo-retal, presença ou não dos critérios de Amsterdã, número de membros da família com câncer colo-retal, número de membros familiares com câncer de endométrio, presença de pacientes com outras neoplasias relacionadas ao $\mathrm{CCHNP}$ e presença de paciente com múltiplos tumores sincrônicos ou metacrônicos. Lipton e colaboradores ${ }^{16}$ também desenvolveram um modelo matemático semelhante ao de Wijnen e colaboradores ${ }^{15}$, evidenciando boa acurácia (sensibilidade e especificidade) na detecção da síndrome.

Apesar da inexistência de consenso na literatura a respeito do mais indicado algoritmo a ser utilizado no rastreamento do CCHNP, há uma tendência a se seguirem algumas etapas na identificação dos portadores da síndrome. $\mathrm{O}$ primeiro passo seria a utilização de critérios clínicos, sendo os de Bethesda os mais amplamente utilizados. Wüllenweber e colaboradores $^{17}$ validaram a utilização dos critérios de Bethesda, demonstrando sensibilidade de $87 \%$ e especificidade de $51 \%$ na detecção de tumores MSI-H. Além disso, esses autores observaram que a presença dos três seguintes critérios (critérios de Amsterdan, câncer colorretal associado a outro câncer em idade inferior a 45 anos e câncer colorretal ou câncer de endométrio em idade inferior a 45 anos) foi capaz de detectar $77 \%$ dos tumores com instabilidade microssatélite de alta freqüência (MSI-H). A partir daí, os indivíduos identificados pelos critérios clínicos seriam submetidos à pesquisa de instabiliade microssatélite no tecido tumoral ou pesquisa da mutação genética por imuno-histoquímica. Southey e colaboradores ${ }^{18}$ demonstraram alta sensibilidade para predição da mutação genética utilizando imunohistoquímica, evidenciando menor custo e maior facilidade de realização do método quando comparado ao seqüenciamento genético pela reação em cadeia da polimerase-PCR. O terceiro passo (padrão ouro) seria a realização do sequenciamento genético.

O GCI recomenda a seguinte vigilância para indivíduos sob risco: colonoscopia iniciada aos 25 anos de idade ou cinco anos antes do diagnóstico de câncer mais jovem na família, que deve ser repetida a cada $1-3 \operatorname{anos}^{19}$. O rastreamento sugerido pela American Society of Colon and Rectal Surgeons (Sociedade Americana de Cirurgiões de Cólon e Reto) é: em pacientes com uma história familiar para CCHNP a colonoscopia deve ocorrer a cada dois anos entre as idades de 21 a 40, e após os 40, anualmente ${ }^{20}$. Para cânceres extra-colônicos, como no caso do câncer de endométrio, não há um consenso. O Cancer Genetics Studies Consortium (Consórcio de Estudos Genéticos para Câncer) recomenda ultrassonografia transvaginal e biópsia aspirativa endometrial a partir dos 25-35 anos e repetidas anualmente ${ }^{21}$. O uso combinado dessas medidas demonstrou uma sensibilidade de $82-97 \%$ e boa especificidade na detecção do câncer endometrial. ${ }^{21,22} \mathrm{~A}$ ultrassonografia transvaginal também pode ser usada no rastreamento do câncer de ovário. Endoscopia digestiva alta pode ser usada naqueles com história familiar de câncer gástrico ou que vivem em área de grande incidência. Para famílias com história de câncer de pelve renal ou ureteral, a análise urinária, a citologia oncótica urinária e ultrassonografia podem ser usados na avaliação do trato urinário superior.

\section{TRATAMENTO}

A indicação de tratamento no CCHNP é mais complexa que na PAF pelo envolvimento de mais genes na síndrome, pela menor penetrância e pela variada expressão clínica. $\mathrm{O}$ planejamento do tratamento é baseado na divisão dos pacientes em três grupos: 1)Pacientes com diagnóstico de CCHNP confirmado que apresentam câncer colo-retal; 2)Pacientes com CCHNP confirmado mas sem câncer e 3)Pacientes de risco para CCHNP mas que não têm condições de realizar o teste genético de predisposição. O primeiro grupo (pacientes com CCR com diagnóstico confirmado de CCHNP) deve ser tratado por colectomia total com íleo-retoanastomose ${ }^{23}$ devido a alta incidência de CCR metacrônico (mais de $40 \%$ em 10 anos). Estes pacientes devem ser acompanhados com exame endoscópico do coto retal remanescente devido ao risco aumentado de câncer. Nos casos em que há tumor retal sem tumor colônico (raridade) pode ser realizado a proctocolectomia total com anastomose íleo-anal com bolsa ileal em J. No segundo grupo que é composto por pacientes sabidamente portadores do defeito genético herdado e sem câncer, existe controvérsia na realização ou não de uma colectomia total profilática (com anastomose íleo-retal), pois como a penetrância do gene que causa a doença está entre $80 \%$ e $90 \%$, estaria-se operando um grupo de pacientes desnecessariamente. Há uma tendência mundial em não realizar cirurgia profilática, sendo a conduta mais aceita o seguimento rigoroso com colonoscopia anual ou bianual, iniciando-se na idade de 25 anos, além de endoscopia digestiva alta e exames de imagem abdominal e pélvica. Para pacientes pós-menopausadas ou que já cumpriram sua atividade reprodutora, a profilaxia cirúrgica através da histerectomia total abdominal com salpingooforectomia bilateral pode ser oferecida, mas não há evidências científicas estabelecidas de sua eficácia ${ }^{21,24}$.

O terceiro grupo (os que não têm condições de realizar o teste genético por algum motivo) deve ser subdividido em pacientes com e sem câncer. Nos pacientes sem câncer que não sabem se são ou não portadores do defeito genético herdado, não deve ser indicado cirurgias profiláticas, e sim seguimento rigoroso com exames periódicos, da mesma forma como se todos fossem portadores do CCHNP. Esse seguimento é feito apesar de sabermos que metade dos indivíduos de uma mesma família não apresentará o defeito genético, de acordo com a herança mendeliana clássica para doença genética autossômica dominante, com um dos pais heterozigoto. Já os que têm câncer devem ser tratados de modo individualizado de acordo com o sitio da lesão, respeitando os princípios de cirurgia oncológica.

\section{POLIPOSE ADENOMATOSA FAMILIAR (PAF)}

Polipose adenomatosa familiar (PAF) é uma síndrome autossômica dominante que predispõe ao câncer colorretal e é responsável por aproximadamente 1\% de todos os casos de câncer colorretal ${ }^{25}$. A herança autossômica dominante significa que cada descendente direto de um paciente portador de PAF tem $50 \%$ de chance de herdar a alteração genética ${ }^{26}$ Aproximadamente um terço dos paci- 
entes acometidos tem mutações de novo no gen APC, ou seja, não herdada. De fato, aproximadamente 22 a $46 \%$ dos casos resultam de novas mutações sem uma associação familiar da doença ${ }^{27}$.

\section{Característica Clínica}

A PAF é caracterizada pelo desenvolvimento de múltiplos pólipos adenomatosos no cólon e reto, usualmente benignos durante a adolescência. $\mathrm{O}$ risco da formação dos adenomas aumenta com a idade: cerca de $15 \%$ aos 10 anos e $90 \%$ aos 30 anos. A média de idade do desenvolvimento dos pólipos é por volta dos 15 anos, embora haja a possibilidade de um pequeno grupo de pacientes não desenvolvê-lo ${ }^{28}$.

Inicialmente são pólipos benignos que progridem para carcinoma aproximadamente por volta dos 35 anos, cerca de 30 anos mais cedo que os cânceres colorretais esporádicos. Os pólipos usualmente são menores que $1 \mathrm{~cm}$. Eles podem ser pediculados ou sésseis, com histologia tubular, túbulo-vilosa ou vilosa. O risco de câncer colorretal é proporcional ao tamanho e ao número de pólipos. A distribuição do câncer colorretal nos portadores de PAF é semelhante ao da população geral, predominando à esquerda. PAF também está associada a um número de lesões extra-colônicas, benignas e malignas que surgem das três camadas embrionárias. Geralmente as manifestações extracolônicas surgem após as manifestações colônicas, porém é possível que tais lesões sejam a manifestação inicial da síndrome ${ }^{29}$.

\section{Manifestações Benignas Extra-Colônicas}

A maioria destas manifestações tem pouco significado clínico, mas são úteis no reconhecimento de indivíduos de famílias afetadas pela síndrome e na identificação de novos casos sem história familiar da doença.

Cisto Epidérmico: Os cistos epidérmicos podem ocorrer em pacientes sem a síndrome, porém nestes indivíduos eles se concentram no dorso. Nos portadores de PAF eles surgem em uma idade mais jovem, muitos anos antes do surgimento dos pólipos colônicos. São caracterizados pela distribuição diferente, acometendo principalmente a face, o couro cabeludo e as extremida$\operatorname{des}^{30}$.

Hipertrofia congênita do epitélio pigmentado da retina: Condição assintomática que serve para identificação de portadores de PAF assintomático. O achado destas lesões tem $68 \%$ de sensibilidade e $100 \%$ de especificidade no diagnostico de indivíduos com PAF. Trata-se de hamartomas do epitélio pigmentado retiniano. Também ocorrem na população geral,entretanto, têm localização unilateral $^{30}$.

Osteomas: Também são lesões que servem para o diagnóstico nos indivíduos assintomáticos. Estão presentes nos ossos da face e do crânio. A normalidades dentárias estão presentes em $70 \%$ dos pacientes com PAF e incluem dentes supranumerários, atópicos ou fusionados. Podem ser encontrados nos ossos da face, mandíbula e calota craniana $^{30}$.

\section{TUMORES EXTRA-COLÔNICOS}

Uma série de outros tumores faz parte da síndrome.

Tumores desmóide: São tumores malignos de comportamento benigno e de crescimento lento. Não tem potencial metastático embora cause grande morbidade e mortalidade pela capacidade de envolvimento, compressão e erosão das estruturas adjacentes. Acometem aproximadamente $10 \%$ dos pacientes portadores de PAF e a maioria, cerca de $70 \%$, são intra-abdominais, sendo que destes, $80 \%$ encontram-se no mesentério do intestino delgado. Os 30\% restantes acometem a parede abdominal e outros sítios. Freqüentemente surgem após o aparecimento dos pólipos intestinais. Alguns fatores de risco têm sido relacionados com o desenvolvimento dos tumores desmóide. O trauma cirúrgico é o principal deles. Oitenta e cinco por cento dos tumores intra-abdominais surgem cerca de cinco anos após procedimentos abdominais, sejam abertos ou por laparoscopia. Os tumores podem ser assintomáticos ou apresentarem-se como volumosas massas, dor abdominal, obstrução intestinal, fístulas, trombose venosa profunda, obstrução urinária ou hemorragia ${ }^{31}$.

Neoplasias no tubo digestivo superior: Incluem pólipos de glândulas fúndicas, antro gástrico e duodenal. Os pólipos de glândulas fúndicas ocorrem em $50 \%$ dos portadores de PAF. Tendem a se acumular no corpo e fundo do estômago e podem surgir antes dos pólipos intestinais. São de natureza hamartomatosa e desprovidos de potencial maligno. Os pólipos duodenais são adenomas com potencial displásico, sendo assim, condição pré-maligna. São encontrados na maioria dos portadores de PAF e surgem em média de 10 a 20 anos após os pólipos intestinais. A polipose duodenal é comum, porém a incidência de adenocarcinoma duodenal na região peri-ampular é de $1 \%$ a $5 \%$. Geralmente a polipose do trato digestivo superior é assintomática e o aparecimento de sintomas sugere transformação maligna no duodeno ou na ampola duodenal. O câncer peri-ampular é a segunda neoplasia maligna mais comumente diagnosticada nos portadores de PAF e é responsável por uma em cada cinco mortes pela doença ${ }^{30}$. Por esta razão, todo paciente com diagnóstico de PAF deve ser submetido a EDA para identificação de lesões associadas do trato digestivo superior.

Neoplasias hepatobiliares: São lesões menos comuns e acometem um pequeno número de pacientes com PAF. Incluem hepatocarcinoma, adenocarcinoma pancreático e colangiocarcinoma.

Carcinomas da tireóide: Há um elevado risco de carcinomas bem diferenciados da tireóide particularmente em mulheres jovens. Como nas formas esporádicas, estes tumores têm bom prognóstico ${ }^{30}$.

Síndrome de Gardner é o termo usado para descrever os pacientes portadores de PAF com fenótipo aparente distinto, em que é encontrado associação com osteomas, cistos epidérmicos e fibromas dérmicos.

Síndrome de Turcot refere-se a associação de pólipos colorretais e a presença de tumores do sistema nervoso central, apresentando-se em dois tipos. O tipo 1 corresponde a pacientes com tumores do sistema nervoso central, usualmente 
gliomas e adenomas colorretais sem polipose. Manchas de pele tipo café-com-leite podem ser encontradas. O tipo 2 é menos comum e inclui pacientes com meduloblastoma em associação com polipose colônica, mais característico de $\mathrm{PAF}^{30}$.

\section{CORRELAÇÃO GENÓTIPO-FENÓTIPO}

A principal alteração genética dos portadores de PAF é a mutação no gene APC (adenomatous poliposis coli). APC é um gene de grande tamanho, com 15 exons e formado por 8538 pares de bases. Este gene codifica uma proteína com 2843 aminoácidos com peso molecular de $310 \mathrm{Kd}$. É classificado como gen de supressão tumoral, uma vez que a inativação de ambos os alelos resulta em crescimento celular desordenado e incontrolável. Os portadores de PAF apresentam mutação em um dos alelos herdados. Existem mais de 300 mutações catalogadas do APC e as mais comuns resultam de inserções ou deleções. Existe uma correlação clara entre a alteração genotípica (tipo e localização) e as características clínicas, ou fenótipo, dos portadores de PAF. Mutação proximal ao códon 1249 é associada com menos de 1000 pólipos distribuídos pelos cólons e mutações presentes entre os códons 1250 e 1330 , com expressão de mais de 5000 pólipos nos cólons. Mutações distais ao códon 1465 estão associadas com poucos pólipos. Aquelas que acontecem na extremidade 5' final do gen (exon 3 e 4) e distais ao códon 1578, na extremidade final 3', são associadas a uma condição clinica branda e variável dita PAF atenuada (PAFa). A PAFa é caracterizada pelo reduzido números de pólipos colorretais $(<100)$ e a idade do aparecimento das lesões é de 10 a 15 anos mais tarde que nos portadores de PAF clássica, embora o risco de desenvolver câncer permaneça inalterado. As mutações presentes entre os códons 312 e 1387 desenvolvem a hipertrofia congênita do pigmento retiniano. Mutações entre os códons 1445 e 1578 estão associadas à gravidade dos tumores desmóides, osteomas, cistos epidermóides e polipose do trato digestivo superior. As correlações entre genótipo e fenótipo descritas em vários estudos sugerem que a localização da mutação não é o único determinante do fenótipo e que outros fatores genéticos e ambientais contribuem para expressão clinica da doença. No futuro poderemos direcionar o tratamento integralmente baseado nas informações genotípicas ${ }^{30}$.

Uma entidade fenotipicamente semelhanye a PAF atenuada não relacionada, porém, à mutação do gen APC, foi recentemente descrita. Tem característica autossômica recessiva e os loci de mutações residem no gen homólogo MutY(MYH), e denominada MAP (polipose associada ao gene MutY homólogo) $)^{32}$.

\section{DIAGNÓSTICO E ACONSELHAMENTO}

O diagnóstico de PAF clássica pode ser feito clinica e endoscopicamente pela identificação de centenas a milhares de pólipos distribuídos pelos cólons e reto. Alterações benignas como cistos epidermóides e hipertrofia congênita do pigmento retiniano presentes ao exame físico servem para reforçar o diagnóstico de PAF. Os pacientes com esta condição reconhecida devem ser investigados com endoscopia digestiva alta, para o diagnóstico de pólipos no estômago e duodeno. A incidência de pólipos duodenais nos pacientes com PAF varia de 80 a $100 \%$, sendo a maioria nas primeiras e segundas porções do duodeno, especialmente na região peri$\operatorname{ampular}^{25}$.

$\mathrm{O}$ reconhecimento individual dos pacientes com fenótipos atenuados ou que se apresentam inicialmente com doença extra-colônicas pode ser menos óbvio e desafiador. Uma vez que o diagnostico de PAF seja feito, todo familiar de primeiro grau do paciente acometido tem $50 \%$ de chance de herdar a mutação familiar específica no APC. Se as mutações familiares podem ser identificadas, testes genéticos são realizados como passo principal na identificação dos familiares que herdaram ou não a mutação no APC. É recomendado que crianças de alto risco sejam submetidas aos testes na idade do 10-11anos. Após a realização dos testes, dois grupos são identificados, aqueles que herdaram as alterações no APC, os quais requerem seguimento e intervenção específica, e aqueles que não herdaram. Os que não herdaram requerem rastreamento semelhante ao da população geral. Nas situações em que o teste genético não seja disponível, recomenda-se exames endoscópicos e oftalmológicos (hipertrofia congênita do pigmento retiniano) como auxiliar no diagnóstico de $\mathrm{PAF}^{30}$ para o grupo de risco (familiares de primeiro grau do paciente).

O paciente deve ser completamente informado dos impactos causados pela realização de testes genéticos, isto inclui desde alterações psicológicas pessoais como ansiedade e depressão, assim como discriminações socioeconômicas, inclusive dos planos de saúde e do mercado de trabalho. $\mathrm{O}$ aconselhamento genético deve ser realizado por profissional treinado e ter o apoio e supervisão de um médico especialista em genética ${ }^{26}$

O diagnóstico genético pré-sintomático nos indivíduos de risco é possível pela detecção direta da mutação do APC. Os testes requerem amostra sanguínea onde o DNA de linfócitos periféricos são testados. A identificação de indivíduos sem mutações no APC remove a necessidade de rastreamento anual, uma vez que a chance de desenvolvimento de câncer neste individuo é a mesma da população geral. Tradicionalmente a avaliação clinica do individuo de risco é feita por completa história pessoal e familiar, exame físico detalhado, sigmoidoscopia flexível anual e colonoscopia quando houver o diagnostico de pólipos. Nos indivíduos positivos para mutações no APC, sigmoidoscopia flexível anual deve ser iniciada aos $10 \operatorname{anos}^{33}$. Somente $15 \%$ dos portadores de mutações no APC desenvolverão pólipos intestinais aos 10 anos; aos 20 anos aproximadamente $75 \%$ dos portadores já apresentam polipose; aos 30 anos $90 \%$ dos portadores apresentam PAF e sem intervenção $100 \%$ dos pacientes desenvolverão câncer colorretal na quarta década de vida ${ }^{25}$.

Não há consenso na literatura sobre rastreamento das outras condições patológicas associadas à PAF. Sugerese que devam ser investigadas com o aparecimento de sintomas.

O diagnóstico diferencial de PAF deve ser feito com câncer colorretal hereditário não polipose (CCHNP), Síndrome de Peutz-Jeghers e Polipose Familiar Juvenil ${ }^{27}$. 


\section{TRATAMENTO}

\section{Tratamento Clínico}

Não existe um tratamento clínico eficaz na completa prevenção do desenvolvimento dos pólipos colorretais nos pacientes com PAF. Drogas anti-inflamtórias não esteroidais (AINE) têm mostrado efeito positivo na regressão do tamanho e na quantidade dos pólipos em alguns pacientes. Não existe ainda uma explicação clara do mecanismo de ação dos AINEs, porém, acredita-se que as prostaglandinas estimulem a tumorigênese pelo aumento da proliferação celular e inibição da apoptose. Os AINEs promovem o bloqueio da formação das prostaglandinas derivadas do ácido araquidônico, pela inibição da atividade da enzima cicloxigenase. $\mathrm{O}$ acido araquidônico também estimula a produção de ceramida, um potente estimulador da apoptose ${ }^{34}$. Os principais AINEs não seletivos estudados são o sulindac, a indometacina e o piroxicam. O uso de sulindac resulta em diminuição do número de pólipos (44\%) e de seu diâmetro (35\%) a partir de quatro meses, principalmente nos pacientes submetidos a colectomia e ileorretoanastomose prévia, porém este efeito não é sustentado após a suspensão da droga. Também deve-se lembrar que o câncer colorretal já foi observado em pacientes com boa resposta ao uso dos AINEs. Estudos recentes apontam resultados promissores com o uso de drogas bloqueadores específicos da isoenzima cicloxigenase 2 (COX 2) com menor índice de efeitos colaterais ${ }^{35}$.

\section{Tratamento Cirúrgico}

Todo portador de PAF requer tratamento cirúrgico. Sabendo-se que 5\% dos portadores de PAF desenvolvem câncer colorretal em torno dos 20 anos e que aproximadamente $100 \%$ dos pacientes desenvolverão câncer na quinta década, a colectomia profilática deve ser praticada num período curto após o diagnóstico clinico de PAF. O risco de câncer não é uniforme, estando relacionado com a intensidade da polipose (a taxa de câncer nos indivíduos com mais de 1000 pólipos é duas vezes maior que nos indivíduos com menos de 1000 pólipos colônicos). Dois objetivos devem ser perseguidos no tratamento cirúrgico de PAF. Em primeiro lugar, toda mucosa colorretal de risco deve ser removida e em segundo lugar, sempre que possível, desde que toda mucosa de risco seja removida, a manutenção da continência anal deve ser tenta$\mathrm{da}^{30}$.

A preservação da função esfincteriana pode ser alcançada por duas técnicas: colectomia total com ileorretoanastomose e a proctocolectomia total restaurativa (PTR). A colectomia total com ileorretoanastomose (conduta de exceção) é reservada para pacientes que apresentam poucos pólipos retais (PAF atenuado) e que estão dispostos a submeter-se a longos períodos de observação com exames endoscópicos a cada seis meses. Os defensores desta técnica argumentam que poucos portadores de PAF morrem por câncer retal após esta operação, sendo o desenvolvimento de tumores no trato digestivo superior a principal causa de óbito, e que os pólipos retais são de fácil tratamento ${ }^{30}$. Por outro lado, cerca de $16 \%$ dos pacientes submetidos a colectomia total necessitarão de protectomia devido ao surgimento de um número elevado de pólipos impedindo um acompanhamento adequado e seguro. A proctocolectomia total restaurativa (reconstrução com bolsa ileal em $\mathrm{J}$ associada à anastomose íleo-anal) se constitui no tratamento padrão. Este procedimento elimina a possibilidade de câncer retal e preserva a função esfincteriana, propiciando qualidade de vida satisfatória. Nyam e colaboradores ${ }^{36}$ reportaram série de 187 pacientes portadores de PAF submetidos a proctocolectomia total restaurativa na Mayo Clinic, evidenciando mediana de quatro evacuações diárias, sendo que apenas $2 \%$ dos pacientes tiveram qualidade de vida prejudicada relacionada a função intestinal.

Pacientes submetidos a PTR não estão imune ao desenvolvimento de pólipos peri-anastomose ou na própria bolsa ileal. Após anastomose íleo-anal utilizando a técnica de duplo grampeamento, um pequeno anel de mucosa retal permanece e pode dar origem a pólipos. A forma de contornar esta situação é a realização da mucosectomia, em que a mucosa do reto distal e do canal anal proximal são removidas, preservando-se a musculatura esfincteriana. Mesmo com este procedimento, o seguimento endoscópico da bolsa ileal está indicado, pois o risco de desenvolvimento de pólipos na bolsa é de 7\% em cinco anos, 35\% em 10 anos e 75\% em 15 anos $^{37}$.

Duas neoplasias associadas a PAF merecem considerações especiais pela sua frequiência e mortalidade. O tumor desmóide é neoplasia de comportamento localmente invasivo sem potencial metastático, referido como "benigno", mas que pode ocasionar significativa morbi-mortalidade, sendo responsáveis pela morte de $10 \%$ a $23 \%$ dos pacientes com $\mathrm{PAF}^{38}$. Raramente ocorrem na população geral e incidem em 12-17\% dos pacientes portadores de PAF. São intra-abdominais em $80 \%$ e surgem em 2-3 anos após colectomia em $80 \%$ dos casos. No abdome, tendem a ser difusamente infiltrativo no mesentério do intestino delgado, sendo intimamente relacionado com os vasos do mesentério. Causam obstrução intestinal por gerarem retrações nas alças intestinais e obstruem os ureteres por invasão direta. A localização mesentérica destes tumores atua como fator limitador nas reconstruções após colectomias uma vez que limita a descida da bolsa ileal à pelve. A ressecção destes tumores, com remoção de extensões variadas do intestino delgado, está associado a elevadas taxas de morbidade e recorrência. Os tumores desmóides envolvendo o mesentério são tratados de acordo com o seu crescimento e suas manifestações clinicas. O tratamento farmacológico inclui a utilização de modeladores hormonais (anti-estrogênios e megestrol), anti-inflamatórios não-esteroidais, quimioterapia citotóxica (doxorrubicina, vinblastina, metrotexate) e outros agentes ( interferon gama, imatinib, etc) A recomendação para tratamento com estas modalidades está baseada em relatos de casos e em séries com casuística limitada. Evidências sugerem resposta parcial ao sulindac, porém não superiores a dois anos. A resposta à terapia com altas doses de antiestrogênicos é incerta, porém há relatos de bons resultados com doses de $120 \mathrm{mg} /$ dia. Outros antiestrogênicos como o toremifene, que é mais potente que o tamoxifeno, tem efeito semelhante e as melhores respostas são descritas em tumores desmóides de pacientes não portadores de PAF. Estudos com agentes antifibrose como a pirfenidona apresentaram resultados mo- 
destos $^{25-27,30}$. Mace e colaboradores ${ }^{39}$ trataram dois pacientes com tumores desmóides recidivados (não associados a PAF) com inibidor de tirosina quinase (imatinib) $800 \mathrm{mg} / \mathrm{dia}$, obtendo redução de $50 \%$ do volume tumoral em um caso e estabilização da lesão no outro.

Os resultados da ressecção cirúrgica dos desmóides intra-abdominais são desanimadores devido a alta morbi-mortalidade relacionado ao procedimento e a altas taxas de recidiva $(\text { até } 85 \%)^{40}$. A radioterapia tem sido utilizada como terapia adjuvante a ressecção cirúrgica de desmóides extra-abdominais, reduzindo a taxa de recorrência em até $30 \%{ }^{41}$.

A segunda localização mais frequiente dos tumores desmóides é a parede abdominal. Nesta localização são de fácil tratamento, sem maiores dificuldades para ressecção embora o uso de próteses para reconstrução seja freqüente. Apresentam baixas taxas de recorrência e baixa morbidade associada à ressecção. Margens de $1 \mathrm{~cm}$ de segurança devem ser respeitadas $^{42}$.

A importância do estudo endoscópico do trato digestivo alto é decorrente da grande incidência (92\% a 98\%) de neoplasia duodenal (pólipos adenomatosos) nos portadores de PAF e da considerável taxa de mortalidade atribuída a esta neoplasia (8\% a $18 \%$ dos portadores de PAF morrerão em decorrência de neoplasias peri-ampulares). Desta forma, todo portador de PAF deve iniciar o rastreamento com endoscopia digestiva alta após 20 anos de idade, com a finalidade de erradicação dos pólipos (ressecção endoscópica) e prevenção do desenvolvimento de carcinomas do trato gastrointestinal alto.

A gravidade da polipose duodenal pode ser classificada segundo Spigelman ${ }^{42}$ (Tabela 3), havendo correlação entre o estadiamento e o risco de desenvolvimento de câncer.

Tabela 3 - Escore de gravidade de pólipos duodenais segundo Spigelman ${ }^{42}$.

\begin{tabular}{lccc}
\hline & \multicolumn{3}{c}{ Escore } \\
& $\mathbf{1}$ & $\mathbf{2}$ & $\mathbf{3}$ \\
\hline No de pólipos & $1-4$ & $5-20$ & $>20$ \\
Tamanho cm & $1-4$ & $5-10$ & $>10$ \\
Histologia & Tubular & Túbulo-viloso & Viloso \\
Displasia & Leve & Moderada & Severa \\
\hline
\end{tabular}

Estádio $0=$ zero pontos, Estádio $I=1-4$ pontos, Estádio $I I=5-6$ pontos, Estádio $I I I=7-8$ pontos, Estádio $I V=9-12$ pontos.

\section{Agradecimentos}

Nossos agradecimentos ao Dr. Fernando Regla Vargas (Doutor em genética pela UFRJ, Professor Adjunto da Faculdade de Medicina UNIRIO e Coordenador do Programa de Aconselhamento Genético do INCA) pela valiosa revisão do manuscrito.

\begin{abstract}
The colorectal cancer has become a world public health problem as a consequence of the great number of new cases which have been diagnosed each year and the existence of some conditions related to the disease's natural history that can be identified and the cancer prevented. Knowing the fact that $20 \%$ out of all colorectal cancers develops as part of a hereditary cancer syndrome, it is crucial that the physician (not only the surgeon) be updated with this entity, being able to recognize, and mainly, implement screening programs to identify family members at risk of developing cancer and to allow the intervention to prevent the occurrence of the adenoma-carcinoma sequence (Rev. Col. Bras. Cir. 2007; 34(3): 193-200).
\end{abstract}

Key words: Colorectal neoplasms; Heredity; Carcinoma/ prevention \& control.

\section{REFERÊNCIAS}

1. Yu HJA, Lin KM, Ota DM, Lynch HT. Hereditary nonpolyposis colorectal cancer: preventive management. Cancer Treat Rev. 2003; 29(6):461-70.

2. Lynch HT, Shaw MW, Magnuson CW, Larsen AL, Krush AJ. Hereditary factors in cancer. Study of two large midwestern kindreds. Arch Intern Med. 1966; 117(2):206-12.

3. Lynch HT, de la Chapelle A. Genetic susceptibility to nonpolyposis colorectal cancer. J Med Genet. 1999; 36(11):801-18.

4. Rousseau DL, Midis GP, Feig BW, et al. Cancer of the colon, rectum, and anus. In: Feig BW, Berger DH, Fuhrman GM, editors. The M.D. Anderson Surgical Oncology Handbook, $3^{\text {rd }}$ ed. Philadelphia: Lippincott Williams \& Wilkins; 2003.

5. Peltomäki P, Vasen HF. Mutations predisposing to hereditary nonpolyposis colorectal cancer: database and results of a collaborative study. The International Collaborative Group on Hereditary Nonpolyposis Colorectal Cancer. Gastroenterology. 1997; 113(4):1146-58.
6. Brose MS, Smyrk TC, Weber B, Lynch HT. Genetic predisposition to cancer. In: Holland JF, Frei EIII, Bast RC, Kufe DW, Pollock RE, Weichselbaum RR, editors. Cancer medicine. $5^{\text {th }}$ ed. Canada: BC Decker; 2000.

7. Lynch HT, Lynch J. Lynch syndrome: genetics, natural history, genetic counseling, and prevention. J Clin Oncol. 2000; 18(21 Suppl):19S-31S.

8. Lynch HT, Lynch JF. Hereditary nonpolyposis colorectal cancer. Semin Surg Oncol. 2000; 18(4):305-13.

9. Vasen HF, Mecklin JP, Khan PM, Lynch HT. The International Collaborative Group on Hereditary Nonpolyposis Colorectal Cancer (GCI-CCHNP). Dis Colon Rectum. 1991; 34(5): 424-5.

10. Watson P, Lin KM, Rodrigues-Bigas MA, Smyrk T, Lemon S, Shashidharan M, Franklin B, Karr B, Thorson A, Lynch HT. Colorectal carcinoma survival among hereditary nonpolyposis colorectal carcinoma family members. Cancer. 1998; 83(2):25966.

11. Vasen HF, Watson P, Mecklin JP, Lynch HT. New clinical criteria for hereditary nonpolyposis colorectal cancer (CCHNP, Lynch 
syndrome) proposed by the International Collaborative Group on CCHNP. Gastroenterology. 1999; 116(6):1453-6.

12. Rodriguez-Bigas MA., Boland CR, Hamilton SR, Henson DE, Jass JR, Khan PM, Lynch H, Perucho M, Smyrk T, Sobin L. A National Cancer Institute Workshop on Hereditary Nonpolyposis Colorectal Cancer Syndrome: meeting highlights and Bethesda guidelines. J Natl Cancer Inst. 1997; 89(23):1758-62.

13. Haydon AM, Jass JR. Emerging pathways in colorectal-cancer development. Lancet Oncol. 2002; 3(2) 83-8.

14. Umar A, Boland CR, Terdiman JP, Syngal S, de la Chapelle A, Ruschoff J, Fishel R, Lindor NM, Burgart LJ, Hamelin R, Hamilton SR, Hiatt RA, Jass J, Lindblom A, Lynch HT, Peltomaki P, Ramsey SD, Rodriguez-Bigas MA, Vasen HF, Hawk ET, Barrett JC, Freedman AN, Srivastava S. Revised Bethesda guidelines for hereditary nonpolyposis colorectal cancer (Lynch syndrome) and microsatellite instability. J Natl Cancer Inst. 2004; 96(4):261-8.

15. Wijnen JT, Vasen HF, Khan PM, Zwinderman AH, van der Klift H, Mulder A, Tops C, Moller P, Fodde R. Clinical findings with implications for genetic testing in families with clustering of colorectal cancer. N Engl J Med. 1998; 339(8):511-8.

16. Lipton LR, Johnson V, Cummings C, Fisher S, Risby P, Sadat AT, Cranston T, Izatt L, Sasieni P, Hodgson SV, Thomas HJ, Tomlinson IP. Refining the Amsterdam Criteria and Bethesda Guidelines: testing algorithms for the prediction of mismatch repair mutation status in the familial cancer clinic. J Clin Oncol. 2004; 22(24):4934-43.

17. Wüllenweber HP, Sutter C, Autschbach F, Willeke F, Kienle P, Benner A, Bahring J, Kadmon M, Herfarth C, von Knebe Doeberitz M, Gebert J . Evaluation of Bethesda guidelines in relation to microsatellite instability. Dis Colon Rectum 2001; 44(9):1281-9.

18. Southey MC, Jenkins MA, Mead L, Whitty J, Trivett M, Tesoriero AA, Smith LD, Jennings K, Grubb G, Royce SG, Walsh MD, Barker MA, Young JP, Jass JR, St John DJ, Macrae FA, Giles GG, Hopper JL. Use of molecular tumor characteristics to prioritize mismatch repair gene testing in earlyonset colorectal cancer. J Clin Oncol. 2005; 23(27):6524-32. Epub 2005 Aug 22.

19. Vasen H, Mecklin JP, Watson P, Utsunomiya J, Bertario L, Lynch P, Svendsen LB, Cristofaro G, Muller H, Khan PM, et al. Surveillance in hereditary nonpolyposis colorectal cancer: an international cooperative study of 165 families. The International Collaborative Group on CCHNP. Dis Colon Rectum. 1993; 36(1):1-4.

20. Simmang C, Senagore P Lowry A, Hicks T, Burnstein M, Dentsman F, Fazio V, Glennon E, Hyman N, Kerner B, Kilkenny J, Moore R, Peters W, Ross T, Savoca P, Vernava A, Wong WD. Practice parameters for detection of colorectal neoplasms. The Standards Committee, the American Society of Colon and Rectal Surgeons. Dis Colon Rectum. 1999; 42(9):1123-9.

21. Burke W, Peterson G, Lynch P, Botkin J, Daly M, Garber J, Khan MJ, McTiernan A, Offit K, Thomson E, Varricchio C. Recommendations for follow-up care of individuals with an inherited predisposition to cancer. I. Hereditary nonpolyposis colorectal cancer. Cancer Genetics Studies Consortium. JAMA. 1997; 277(11):915-9.

22. Van den Bosch T, Vandendael A, Van Schoubroeck D, Wranz PA, Lombard CJ. Combining vaginal ultrasonography and office endometrial sampling in the diagnosis of endometrial disease in postmenopausal women. Obstet Gynecol. 1995; 85(3):345-52.

23. Rodriguez-Bigas M, Vasen HF, Pekka-Mecklin J, Myrhøj T, Rozen P, Bertario L, Järvinen HJ, Jass JR, Kunitomo K, Nomizu T, Driscoll DL. Rectal cancer risk in hereditary nonpolyposis colorectal cancer after abdominal colectomy. Ann Surg. 1997; 225(2):202-7.
24. DeCosse JJ. Surgical prophylaxis of familial colon cancer: prevention of death from familial colorectal cancer. J Natl Cancer Inst Monogr. 1995; (17):31-2.

25. Campbell WJ, Spence RA, Parks TG. Familial adenomatous polyposis. Br J Surg. 1994; 81(12):1722-33.

26. Herrea L. Familial adenomatous polyposis. New York: Alan R. Liss; 1990.

27. Eng C, Hampel H, de la Chapelle A. Genetic testing for cancer predisposition. Annu Rev Med. 2000; 52:371-400. Erratum in: Annu Rev Med 2002:53:xi

28. Lynch HT, Tinley ST, Lynch J, Vanderhoof J, Lemon SJ. Familial adenomatous polyposis. Discovery of a family and its management in a cancer genetics clinic. Cancer. 1997; 80 (Suppl 3):614-20.

29. Rustgi AK. Hereditary gastrointestinal polyposis and nonpolyposis syndromes. N Engl J Med. 1994; 331(25):16941702.

30. Lal G, Gallinger S. Familial adenomatous polyposis. Sem Surg Oncol. 2000; 18:314-323.

31. Clark SK, Phillips RK. Desmoids in familial adenomatous polyposis. Br J Surg. 1996; 83(11):1494-504.

32. Galiatsatos P, Foulkes WD. Familial adenomatous polyposis. Am J Gastroenterol. 2006; 101(2):385-98.

33. Powel SM, Petersen GM, Krush AJ, Booker S, Jen J, Giardiello FM, Ha,ilton SR, Vogelstein B, Kinzler KW. Molecular diagnosis of familial adenomatous polyposis. N Eng J Med. 1999; 329(27):1982-7.

34. Chan TA, Morison PJ, Volglstein B, Kinzler KW. Mechanisms underlying nonsteroidal antiinflammatory drug-mediated apoptosis. Proc Natl Acad Sci. 1998; 95(2):681-6.

35. Elder DJ, Paraskeva C. COX-2 inhibitors for colorectal cancer. Nat Med. 1998; 4(4):392-3.

36. Nyam DC, Brillant PT, Dozois RR, Kelly KA, Pemberton JH, Wolff BG. Ileal pouch-anal canal anastomosis for familial adenomatous polyposis: early and late results. Ann Surg. 1997; 226(4):514-9; discussion 519-21.

37. Parc YR, Moslein G, Dozois RR, Pemberton JH, Wolff BG, King JE. Familial adenomatous polyposis: results after ileal pouch-anal anastomosis in teenagers. Dis Colon Rectum. 2000; 43(7):893-8; discussion 898-902.

38. Bulow S. Incidence of associated diseases in familial polyposis coli. Semin Surg Oncol. 1987; 3(2):84-7.

39. Mace J, Sybil Biermann J, Sondak V, McGinn C, Hayes C, Thomas D, Baker L. Response of extraabdominal desmoid tumors to therapy with imatinib mesylate. Cancer. 2002; 95(11):23739.

40. Jones IT, Jagelman DG, Fazio VW, Lavery IC, Weakley FL, McGannon E. Desmoid tumors in familial polyposis coli. Ann Surg. 1986; 204(1):94-7.

41. Moslein G, Dozois RR. Desmoid tumors associated with familial adenomatous polyposis. Perspect Colon Rectal Surg. 1998; 10(2):109-26.

42. Wallace MH, Phillips RK. Upper gastrointestinal disease in patients with familial adenomatous polyposis. Br J Surg. 1998; 85(6):742-50.

Como citar este artigo:

Valadão M, Castro LS. Câncer colo-retal hereditário. Rev Col Bras Cir. [periódico na Internet]. 2007; 34(3). Disponível em URL: http:/ /www.scielo.br/rcbc

Endereço para correspondência:

Marcus Valadão

Rua Paissandu, 385/302 - Flamengo

22210-080 - Rio de Janeiro - RJ

E-mail:marcusvaladao@terra.com.br 